\title{
BENTUK DAN CIRI ADJEKTIVA BAHASA DAYAK NGAJU
}

\section{(FORMS AND CHARACTERISTICS OF DAYAK NGAJU LANGUAGE)}

\author{
Elisten Parulian Sigiro \\ Balai Bahasa Provinsi Kalimantan Tengah \\ Pos el: giro_pky@yahoo.com
}

Diterima: 19 Juli 2016; Direvisi: 03 Agustus 2016; Disetujui: 10 November 2016

\begin{abstract}
The method used in this research is descriptive qualitative methods and techniques in this study reflect the reality on the facts (fact findings) that is in the field as it is. This research examines how the shape and characteristics of adjectives in BDNg. Thus, the researchers sought to describe objectively and accurately in accordance with the aspects of adjectives BDNg current conditions. In practice, this is done through two methods of data collection techniques, namely by using interview and documentation techniques. The findings of this research, that adjective BDNg can be marked by characteristic, namely (1) there is a possibility to join the particle beken 'not' and dia 'no' (2) can accompany a noun, or (3) may be accompanied by words labih 'more', pangka 'most', tutu 'very', and labien 'very'. Meanwhile, based on variations in shape, adjectives can be distinguished BDNg its kind on the basis adjectives and adjectival derivative. Basic adjectives are adjectives that only consist of a single morpheme. Meanwhile, the derivative adjective derivative form BDNghave formed through the process of moving on word class and morphological processes, namely affixation, reduplication and compounding. Based their category, there is only one category of adjectives of adjectives BDNg, the adjectives predicative (adjectives that could occupy the position of the predicate in the clause). Furthermore, in its formation, adjectives BDNg formed through some process of affixation, reduplication and compounding.
\end{abstract}

Key words: descriptive, qualitative, morphological, adjectives

\begin{abstract}
Abstrak
Metode yang digunakan dalam penelitian ini adalah metode deskriptif kualitatif karena metode dan teknik penelitian ini mencerminkan kenyataan berdasarkan fakta-fakta (fact findings) yang ada di lapangan sebagaimana adanya. Penelitian ini mengkaji bagaimana bentukdan ciriadjektiva dalam BDNg. Dengan demikian, peneliti berusaha menggambarkan secara objektif dan tepat aspek adjektiva BDNg sesuai dengan kondisi BDNg saat ini. Dalam pelaksanaannya, metode ini dilakukan melalui dua teknik pengumpulan data, yakni dengan menggunakan teknik wawancara dan teknik dokumentasi. Adapun temuan penelitian ini, yakni adjektiva BDNg dapat ditandai dengan ciri, yaitu (1) ada kemungkinan untuk bergabung dengan partikel beken 'bukan' dan dia 'tidak'(2) dapat mendampingi nomina, atau (3) dapat didampingi kata labih 'lebih', pangka 'paling', tutu 'sangat', dan labien 'sangat'. Sedangkan berdasarkan variasi bentuk, adjektiva BDNg dapat dibedakan jenisnya atas adjektiva dasar dan adjektiva turunan. Adjektiva dasar adalah adjektiva yang hanya terdiri atas satu morfem. Sementara itu, adjektiva turunan BDNg mempunyai bentuk turunan yang terbentuk melalui proses pindah kelas kata dan proses morfologis, yaitu afiksasi, reduplikasi, dan pemajemukan. Berdasarkan katergorinya, adjektiva BDNg hanya ada satu kategori adjektiva, yaitu adjektiva predikatif (adjektiva yang dapat menempati posisi predikat dalam klausa). Selanjutnya, dalam pembentukannya, adjektiva $\mathrm{BDNg}$ dibentuk melalui beberapa proses afiksasi, reduplikasi, dan pemajemukan.
\end{abstract}

Kata kunci: deskriptif, kualitatif, morfologis, adjektiva 
1. Pendahuluan

1.1 Latar Belakang

Bahasa Dayak Ngaju merupakan

salah satu bahasa daerah yang terdapat di wilayah Provinsi Kalimantan Tengah.

Dari sekian banyak bahasa daerah di provinsi ini, bahasa Dayak Ngaju memiliki populasi penutur yang sangat besar. Tidaklah mengherankan kalau bahasa ini menjadi lingua franca bagi masyarakat Kalimantan Tengah pada umumnya. Bahkan penggunaan bahasa daerah ini dijadikan sebagai salah satu bahan ajar (muatan lokal) di sekolah dasar maupun di sekolah lanjutan tingkat pertama.

Bahasa Dayak Ngaju dipandang sebagai satu-satunya bahasa yang memenuhi persyaratan sebagai sebuah bahasa yang wajib dilestarikan. Stewart dalam Elbaar (1995:10) mempostulatkan empat klasifikasi sebuah bahasa, antara lain:

1) kebakuan struktur (standardization), 2) kemandirian bahasa (autonomy), 3) kesejarahannya (historicity), dan 4) keterpakaian (vitality). Penguasaan wilayah tutur bahasa Dayak Ngaju di Kalimantan Tengah tidak lepas dari peran para misionar yang melakukan penginjilan di Kalimantan Tengah pada tahun 1935. Sebelumnya, yakni pada tahun 1922, K.D. Epple telah membuat daftar kata dan petunjuk/tata bahasa Dayak Ngaju, di dalam bukunya yang berjudul Soerat Logat Basa Ngadjoe, menyusul sebelas tahun kemudian, yakni tahun 1933, diterbitkan pula Kurze Einführung In die Ngadjoe-Dajaksprache. Selanjut-nya, pada tahun 1859 , telah dikodifikasi dan diterbitkan sebuah kamus berbahasa Dayak-Jerman oleh Hardeland. Satusatunya penutur asli yang menulis tentang pelajaran bahasa Dayak Ngaju setelah para peneliti asing adalah Tjilik Riwut, yakni Peladjaran Bahasa Dajak Ngadju (1970).

Penelitian-penelitian lain tentang bahasa Dayak Ngaju telah banyak 
dilakukan, di antaranya Struktur Bahasa pembentukan adjektiva dalam BDN, Dayak Ngaju oleh Santoso, dkk. (1991), penelitian ini dibatasi pada beberapa hal, Upon Ajar Bahasa Dayak Ngaju atau antara lain sebagai berikut.

Pokok Ajaran Bahasa Dayak Ngaju oleh (1) Apa saja jenis-jenis (bentuk) Bingan, dkk. (2001), dan lain- adjektiva dalam BDN?

lain.Menyikapi pentingnya kodifikasi (2) Apa saja kategori adjektiva dalam bahasa Dayak Ngaju (karena bahasa $\mathrm{BDN}$ ?

Dayak Ngaju sebagai linguafranca di

(3) Bagaimanakah proses pem-bentukan Kalimantan Tengah) bagi kepentingan adjektiva dalam BDN?

pembinaan dan pengembangannya, pada

\subsection{Tujuan Penelitian}

tulisan ini (untuk menutupi kerumpangan

yang terdapat pada penelitian sebelumnya) akan menyelisik aspek bentuk dan ciri adjektiva bahasa Dayak Ngaju (bahasa Dayak Ngaju selanjutnya dalam tulisan ini disingkat $\mathrm{BDNg}$ ).

\subsection{Masalah}

Penelitian ini mengkaji jenis, kategori, dan proses pembentukan adjektiva dalam BDN.

\subsection{Batasan Masalah}

Dalam mengungkapkan permasalahan jenis, kategori dan proses
Secara umum, penelitian adjektiva dalam BDN ini dilakukan dengan tujuan untuk:

(1) mendeskripsikan jenis-jenis adjektiva dalam BDN;

(2) mendeskripsikan kategori adjektiva dalam BDN, dan

(3) mendeskripsikan proses pembentukan adjektiva dalam BDN. Hal yang tidak kalah penting diharapkan dari penelitian ini untuk memberikan sumbangsih bagi khazanah penelitian linguistik di Indonesia. 


\section{Kerangka Teori}

Terkait penelitian ini, diuraikan batasan konsep dasar kelas kata adjektivadan pendeskripsian kaidah jenis (bentuk), ketegori, $\quad$ serta proses — keadilan, halus — kehalusan, yakin pembentukannya.

\subsection{Adjektiva}

Menurut Kridalaksana (2007:68), adjektiva adalah kategori yang ditandai oleh kemungkinannya untuk bergabung dengan partikel "tidak", (2) mendampingi nomina, (3) didampingi partikel, seperti lebih, sangat, agak, (4) mempunyai ciri-ciri morfologis, seperti er (dalam honorer), -if (dalam sensitif), $-i$ (dalam alami) atau (5) dibentuk menjadi nomina dengan konfiks ke-an, seperti adil keyakinan (ciri terakhir ini berlaku bagi sebagian besar adjektiva dasar dan bisa menandai verba intransitif, jadi ada tumpang tindih di antaranya).

\subsection{Bentuk Adjektiva}

Berdasarkan bentuk, adjektiva dapat dibedakan atas beberapa jenis.

a) Adjektiva Dasar

1) yang dapat diuji dengan kata sangat, lebih, misalnya:

$\begin{array}{llll}\text { adil } & \text { bagus } & \text { cemberut } & \text { deras } \\ \text { afdol } & \text { bahagia } & \text { celaka } & \text { disiplin } \\ \text { agung } & \text { baik } & \text { cemas } & \text { dungu } \\ \text { aib } & \text { bangga } & \text { cepat } & \text { durhaka } \\ \text { ajaib } & \text { baru } & & \\ \text { cerdas } & \text { durjana } & & \end{array}$

2) yang tidak dapat diuji dengan kata sangat, lebih, misalnya:

$\begin{array}{llll}\text { buntu } & \text { genap } & \text { langsung } & \text { pelak } \\ \text { cacat } & \text { interlokal } & \text { laun } & \text { tentu } \\ \text { gaib } & \text { kejur } & \text { musnah } & \text { tunggal } \\ \text { ganda } & \text { lancing } & \text { niskala } & \end{array}$


b) Adjektiva Turunan

Selain bentuk dasar, adjektiva mempunyai bentuk turunan yang terbentuk melaui proses afiksasi, reduplikasi, pemajemukan (subordinatif dan koordinatif). Selain itu, adjektiva juga memiliki bentuk turunan pindah kelas yang terbentuk melalui proses:

1) pembentukan adjektiva dari kelas verba ke kelas adjektiva atau yang disebut deverbalisasi seperti: melengking, melepuh, melimpah, meluap, memalukan, membenci menggoda, mengganggu, menggembirakan.

2) pembentukan adjektiva dari kelas nomina ke kelas adjektiva atau yang disebut nominalisasi, seperti: anginangin, atas, bawah, belakang, berakar,berapi-api, berhati-hati.

3) pembentukan adjektiva dari kelas adverbial ke kelas adjektiva atau yang disebut deadverbialisasi, seperti: berkurang, berlebihan, bertambah, melebih, menyengat, mungkin.

4) pembentukan adjektiva dari kelas numeralia ke kelas adjektiva atau yang disebut denumeralisasi seperti: manunggal, mendua, menyeluruh.

5) pembentukan adjektiva dari kelas interjeksi ke kelas adjektiva atau yang disebut de-interjeksi, seperti: aduhai, wah, sip, asoi, yahud.

\subsection{Kategori Adjektiva}

Ada dua macam kategori adjektiva, yaitu:

1) adjektiva redikatif, yaitu adjektiva yang dapat menempati posisi predikat dalam kalusa, misalnya hangat, sulit, mahal.

2) adjektiva atributif, yaitu adjektiva yang mendampingi nomina dalam pfrase nominal, misalnya nasional, niskala.

Pada umumnya, adjektiva predikatif dapat berfungsi secara atributif, 
sedangkan ajektiva atributif tidak dapat berfungsi secara predikatif.

1) adjektiva bertaraf, yakni yang dapat berdampingan dengan agak, sangat, dan sebagainya, seperti pekat, makmur.

2) ajektifa tak bertaraf, yakni yang tidak dapat berdampingan dengan agak, sangat, dan sebagainya, seperti nasional, intern.

\subsection{Proses Pembentukan Adjektiva}

Adjektiva dibentuk melalui beberapa proses, di antaranya:

1) afiksasi, misalnya terhormat,

2) berafikske-R-an atau ke-an, misalnya: kebelanda-belandaan, kemalumaluan, kesakitan, kesepian,

3) berafiks- $i$ (atau alomorfnya), misalnya: abadi, alami, duniawi, grejani, hewani,

4) reduplikasi, misalnya: muda-muda, elok-elok, ringan-ringan, gagahgagah, dan
5) Pemajemukan:

a) adjektiva koordinatif (komponenkomponennya ber-status sederajat), misalnya: besar mulut, buta huruf, buta warna, keras kepala, keras hati, dan

b) adjektiva subordinatif (kopmponen-komponenya berstatus berlainan): gagah berani, cantik jelita, lemah gemulai, lemah lembut.

\section{Metode Penelitian}

\subsection{Metode}

Metode yang digunakan dalam penelitian ini adalah metode deskriptif kualitatif karena metode dan teknik penelitian ini mencerminkan kenyataan berdasarkan fakta-fakta (fact findings) yang ada di lapangan sebagaimana adanya (Nawawi dan Hadari, 1967:78). Dengan demikian, peneliti berusaha menggambarkan secara objektif dan tepat 
aspek adjektiva BDNg sesuai dengan strata sosial pemakaian bahasa tersebut kondisi BDNg saat ini.

supaya data yang diperoleh lebih

Dalam pelaksanaannya, metode komprehensif dan representatif.

ini dilakukan melalui dua teknik pengumpulan data, yakni dengan menggunakan teknik wawancara dan teknik dokumentasi (Chaer, 2007:58). Teknik wawancara dalam penelitian ini adalah teknik wawancara terbuka atau yang sering dikenal dengan sebutan wawancara tidak terstruktur (unstructurized interview). Wawancara tidak terstruktur atau terbuka ini digunakan dengan tujuan untuk memperoleh informasi sebanyakbanyaknya tentang adjektiva yang ada pada BDNg tanpa harus membatasi tuturan percakapan responden yang diwawancarai. Untuk mendapatkan gambaran permasalahan yang lebih lengkap, peneliti perlu melakukan wawancara kepada responden yang mewakili berbagai wilayah pengguna BDNg serta yang mewakili tingkatan

\subsection{Sumber Data}

Data yang digunakan dalam penelitian ini berupa semua adjektiva dalam BDNg. Sumber data pada penelitian ini adalah informan/penutur asli BDNg, sedangkan yang menjadi rujukan data untuk penelitian ini adalah korpus data adjektiva dalam $\mathrm{BDNg}$, dan dokumen penelitian terdahulu tentang morfologi $\mathrm{BDNg}$, terutama yang membahas tentang adjektiva.

Data primer penelitian ini ialah data yang disediakan oleh peneliti berasal dari penutur asli BDNg (populasi). Sesuai dengan tujuan yang hendak dicapai penelitian ini, yakni deskripsi struktur adjektiva, dalam penelitian ini tidak dipakai populasi dalam jumlah besar, tetapi hanya sejumlah kecil informan (sebagai pemerdata/sampel) yang dipilih menurut syarat-syarat penentuan 
informan yang memenuhi syarat. Samarin berbahasa BDNg (Lembaga Alkitab (1988:28) mengatakan bahwa seseorang Indonesia, 1999) dan ditambah dari hasil yang meneliti suatu bahasa dengan tujuan wawancara dengan beberapa informan. menemukan deskripsi struktural bahasa Adjektiva yang berhasil dihimpun dari itu sebenarnya memerlukan tidak lebih percakapan informan dan Alkitab disusun seorang informan yang baik.

dalam sebuah pangkalan data (database)

Sejalan dengan syarat pemilihan untuk membangun sebuah korpus data. informan, informan dalam penelitian ini Adjektiva-adjektiva ini telah diklasifikasi sebanyak empat informan yang berasal berdasarkan proses morfologis dari Desa Pulau Telo, Kecamatan Pulau pembentukannya. Beberapa dokumen Petak, Kabupaten Kapuas. Pimilihan penelitian yang menjadi perbandingan wilayah penelitian ini berdasarkan asumsi penyusunan penelitian ini adalah bahwa dialek Pulau Petak digunakan para "Pemerian Morfologi Bahasa Dayak misionaris dalam penulisan Surat Barasi Ngaju" (KMA. M. Usop, 1975), dan (Alkitab). Dengan demikian, dialek Pulau "Struktur Bahasa Dayak Ngaju" (Dewi Petak telah banyak digunakan masyarakat Mulyani Santosa, dkk., 1991).

dalam acara kebaktian di gereja sehingga masyarakat lebih mengenal kosa kata BDNg dialek Pulau Petak.

Data sekunder penelitian ini (data yang sudah tersedia dari berbagai tulisan) penelitian. Teknik-teknik tersebut adalah: berasal dari tulisan, seperti korpus data dan dokumen penelitian. Korpus data

1) Teknik rekam dan kerja sama dengan informan penelitian ini berasal dari Alkitab (Bible)

\subsection{Teknik Pengumpulan Data}

Menurut Soebroto (2007), ada beberapa teknik yang digunakan untuk mengumpulkan data dalam sebuah 
Teknik ini digunakan untuk merekam ujaran lisan yang spontan dari seorang informan. Medium yang digunakan adalah alat perekam mini. Satuan kebahasaan kemudian kita minta untuk diucapkan secara wajar dan normal oleh informan secara bergantiganti. Dalam melaksanakan metode ini, peneliti perlu bekerja sama dengan informan. Teknik kerja sama dengan informan ini mirip dengan teknik wawancara. Yang membedakannya adalah teknik ini bersifat eksperimental. Bersifat eksperimental di sini berarti peneliti meminta kepada informan agar menanggapi kalimat-kalimat atau satuan bahasa lain yang berisi data tertentu. Teknik ini mempunyai keuntungan, yaitu data yang diperoleh benar-benar sahih dan mencegah peneliti untuk cenderung membenarkan hipotesisnya.

2) Teknik simak dan catat
Yang dimaksud dengan metode simak dan catat adalah mengadakan penyimakan terhadap pemakaian bahasa lisan yang bersifat spontan dan mengadakan pencatatan terhadap data relevan yang sesuai dengan sasaran dan tujuan penelitian. Data yang relevan biasanya dicatat lengkap dengan konteks latarnya, yaitu keterangan singkat yang melatarbelakangi terdapatnya data relevan. Media yang digunakan adalah satu set alat tulis.

3) Teknik studi pustaka Yang dimaksud dengan teknik studi pustaka adalah menggunakan sumbersumber tertulis untuk memperoleh data. Sumber tertulis yang digunakan dipilih yang mencerminkan pemakaian bahasa sinkronis. Sumbersumber tertulis tersebut dapat berupa buku, kamus, majalah, artikel, dan sebagainya. 
Teknik pengumpulan data lainnya lainnya. Teknik distribusional ini dalam penelitian ini adalah studi selanjutnya dibagi lagi menjadi (1) teknik dokumen. $\quad$ Menurut Sugiyono urai unsur terkecil, yaitu mengurai suatu (2009:329), studi dokumen merupakan satuan lingual tertentu atas unsur-unsur pelengkap penggunaan metode observasi terkecilnya dan (2) teknik urai/pilah unsur dan wawancara dalam penelitian langsung, yaitu memilah suatu konstruksi kualitatif. Sugiyono juga menekankan tertentu atas unsur-unsur langsungnya bahwa hasil penelitian dengan metode (unsur langsung adalah unsur yang secara observasi atau wawancara akan dapat langsung membentuk konstruksi yang dipercaya/lebih kredibel apabila didukung lebih besar). dengan studi dokumen tentang masalahmasalah terkait. Dengan demikian, dua teknik pengumpulan data inilah yang dianggap paling relevan pada penelitian ini.

\subsection{Teknik Analisis Data}

Teknik yang digunakan dalam menganalisis data adalah teknik

\section{Pembahasan}

\subsection{Batasan dan Ciri Adjektiva}

Adjektiva adalah kata yang menerangkan nomina (kata benda) dan secara umum dapat bergabung dengan kata lebih dan sangat. Adjektiva BDNg dapat ditandai dengan ciri. yaitu (1) ada kemungkinan untuk bergabung dengan distribusional. Menurut Soebroto, teknik partikel beken 'bukan' dan dia 'tidak'(2) distribusional didasarkan atas perilaku dapat mendampingi nomina, atau (3) atau tingkah laku satuan-satuan lingual dapat didampingi kata labih 'lebih', tertentu yang teramati dalam pangka 'paling', tutu 'sangat', dan labien hubungannya dengan satuan lingual 'sangat'. 


\section{Data 01}

dia 'tidak' + bahandang 'merah' $\rightarrow$ dia bahandang 'tidak merah'

dia 'tidak' + basingi 'marah' $\rightarrow$ dia basingi 'tidak marah'

labih 'lebih' + paringkong 'kurus' $\rightarrow$ labih paringkong 'lebih kurus'

pangka 'paling' + hai 'besar' $\quad \rightarrow$ pangka hai 'paling besar'

harati 'pintar' + tutu 'sangat' $\rightarrow$ harati tutu 'sangat pintar'

labien 'sangat' + bakena 'cantik/tampan' $\rightarrow$ labien bakena 'sangat cantik/tampan'

\subsection{Jenis Adjektiva}

Berdasarkan variasi bentuk,

adjektiva $\mathrm{BDNg}$ dapat dibedakan

jenisnya atas adjektiva dasar dan adjektiva turunan.

\subsubsection{Adjektiva Dasar}

Adjektiva dasar adalah adjektiva yang hanya terdiri atas satu morfem.

$\begin{array}{ll}\text { Data 02 } & \\ \text { bahalap } & \text { 'cantik' } \\ \text { hanjak } & \text { 'gembira' } \\ \text { taheta } & \text { 'baru' } \\ \text { maram } & \text { 'busuk' } \\ \text { bakas } & \text { 'tua' } \\ \text { tabela } & \text { 'muda' } \\ \text { paringkong } & \text { 'kurus' } \\ \text { baseput } & \text { 'gemuk' } \\ \text { pehe } & \text { 'sakit' }\end{array}$

$\begin{array}{ll}\text { tamam } & \text { 'sombong' } \\ \text { hai } & \text { 'besar' } \\ \text { mameh } & \text { 'bodoh' } \\ \text { kaput } & \text { 'gelap' } \\ \text { taheta } & \text { 'baru' } \\ \text { balau } & \text { 'lapar' } \\ \text { kurik } & \text { 'kecil' } \\ \text { benyem } & \text { 'diam' } \\ \text { lumbah } & \text { 'luas' } \\ \text { gantung } & \text { 'tinggi' } \\ \text { mangat } & \text { 'enak' }\end{array}$

\subsubsection{Adjektiva Turunan}

Adjektiva turunan $\mathrm{BDNg}$ mempunyai bentuk turunan yang terbentuk melalui proses pindah kelas kata dan proses morfologis, yaitu afiksasi, $\quad$ reduplikasi, dan pemajemukan.

1) Adjektiva turunan yang terbentuk dari proses pemindahan kelas kata

\section{Data 03}

$\begin{array}{llc}\text { apui 'api' } & \rightarrow & \text { baapui-apui 'berapi-api' } \\ \mathrm{N} & & \mathrm{A} \\ \text { putak 'busa' } & \rightarrow & \text { baputa-putak 'berbusa-busa' } \\ \mathrm{N} & & \mathrm{A}\end{array}$


2) Adjektiva turunan yang terbentuk dari proses afiksasi

\section{Data 04}

\begin{tabular}{|c|c|}
\hline darem 'demam' & badarem 'meriang' \\
\hline A & A \\
\hline busau 'mabuk' & $\rightarrow$ babusau 'mabuk' \\
\hline $\mathrm{A}$ & A \\
\hline pehe 'sakit' & $\rightarrow$ kapehe 'kesakitan' \\
\hline
\end{tabular}

\subsection{Kategori Adjektiva}

predikatif. Adjektiva predikatif adalah

Dalam BDNg, hanya ada satu adjektiva yang dapat menempati posisi kategori adjektiva, yaitu adjektiva predikat dalam klausa.

\section{Data 05}

1) lasu-lasut 'hangat' $\rightarrow$ danum te lasu-lasut 'air itu hangat'

2) bahali $\quad$ 'sulit' $\quad \rightarrow$ gawi te bahali $\quad$ 'pekerjaan itu sulit'

3) larang 'mahal' $\rightarrow$ lauk tuh larang $\quad$ 'ikan ini mahal'

\subsection{Proses Pembentukan Adjektiva \\ 1) Afiksasi}

Adjektiva BDNg dibentuk melalui beberapa proses afiksasi, reduplikasi, dan pemajemukan.
Proses pembentukan adjektiva dalam $\mathrm{BDNg}$ melalui afiksasi dapat dicontohkan sebagai berikut.

\section{Data 06}

a) Prefiks $b a$ -

ba- + darem

Pre A

$\rightarrow \quad$ badarem 'meriang'

ba- + singi $\rightarrow$ basingi 'marah'

Pre N

A

$b a-+$ daham

Pre A

$\rightarrow \quad$ badaham 'rakus'

A

b) Prefiks $k a$ -

$k a-+$ labien 'lebih' $\rightarrow \quad$ kalabien 'berlebihan'

Pre A

A

$k a-+$ kuntep 'penuh'

Pre

A

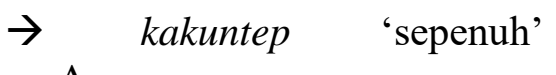


c) Prefiks $p a N$ paN- + kabehu 'cemburu' $\rightarrow$ pangabehu 'mudah cemburu' Pre N A paN- + kamue 'manja' $\rightarrow$ pangamue 'kemanja-manjaan' Pre N A

d) Prefiks sakasaka- + tutu 'sungguh' $\rightarrow$ sakatutu 'sesungguh; sebenar' Pre Adv A saka- + lepah 'habis' $\rightarrow$ sakalepah 'sehabis'

Pre Adv A

2) Reduplikasi

pengulangan dalam $\mathrm{BDNg}$ dapat

Proses pembentukan adjektiva digolongkan dalam bentuk-bentuk melalui mekanisme reduplikasi atau pengulangan berikut.

a) Pengulangan Seluruh

\section{Data 07}

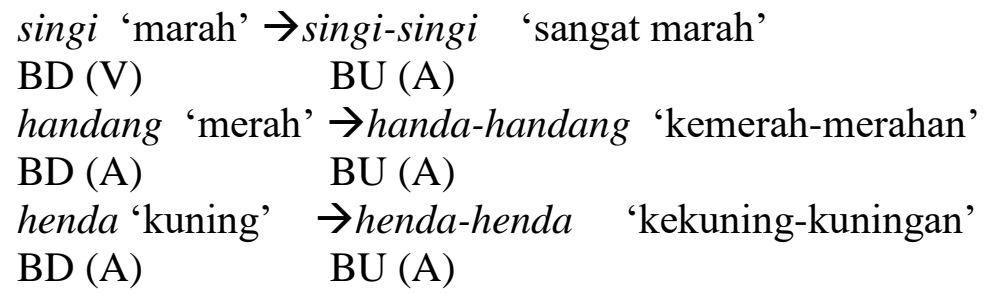

Bentuk dasar singi yang terletak jajar kedua merupakan bentuk ulangnya, pada jajar pertama merupakan bentuk dengan pengulangan bentuk tersebut dasar, sedangkan singi yang terletak pada maka terbentuklah kata ulang singi-singi.

b) Pengulangan Sebagian

\section{Data 08}
(a) ba + kena 'cantik' $\rightarrow$ bakena-kena 'cantik-cantik'
Pre A
$\mathrm{BU}(\mathrm{A})$
(b)
ba + dengen 'tuli' $\rightarrow$ badenge-dengen 'tuli-tuli'
Pre A BU (A)
(c)
ma + hamen 'malu' $\rightarrow$ mahame-hamen 'malu-malu'
Pre A BU (A) 
(d)

$b a+$ darem 'dingin' $\rightarrow$ badare-darem 'dingin-dingin'

$\begin{array}{ll}\text { Pre A } & \text { BU (A) } \\ b a+\text { tekang 'keras', } & \rightarrow \text { bateka-tekang 'keras-keras' } \\ \text { Pre A } & \text { BU (A) }\end{array}$

Proses reduplikasi pembentuk adjektiva dibedakan dalam dua jenis, yakni (1) BDNg terdapat dalam dua bentuk adjektiva koordinatif (kompomepengulangan saja, yakni pengulangan komponennya berstatus sederajat) dan (2) seluruh dan pengulangan sebagian. adjektiva subordinatif (kopmponen-

\subsubsection{Pemajemukan komponenya berstatus berlainan).}

Proses pemajemukan dalam

pembentukan adjektiva $\mathrm{BDNg}$ dapat

\section{Data 09}

1) Adjektiva koordinatif

sala 'salah' + buah'benar' $\rightarrow$ sala buah 'baik buruk'

kurik 'kecil' + hai 'besar' $\rightarrow$ kurik hai 'besar kecil'

bakena 'cantik' + bahalap 'jelita' $\rightarrow$ bakena bahalap 'cantik jelita'

mamut 'gagah' + menteng 'perkasa' $\rightarrow$ memuat mameteng 'gagah perkasa'

lemu 'lemah' + lembai 'gemulai' $\rightarrow$ lemu lembai 'lemah gemulai'

bakas 'tua' + tabela 'muda' $\rightarrow$ bakas tabela 'tua muda'

2) Adjektiva subordinatif

hai 'besar' + takuluk 'kepala' $\rightarrow$ hai takuluk 'besar kepala'

batekang 'keras' + atei 'hati' $\rightarrow$ batekangatei 'keras hati'

kahian 'iklas' + atei'hati' $\rightarrow$ kahian atei 'rela; ikhlas'

rutik 'ramah'+ ampah 'sampah' $\rightarrow$ rutik ampah 'sampah; tak berguna'

banipis 'tipis' + pinding 'telinga' $\rightarrow$ banipis pinding 'perasa'

mait 'ampuh' + jela 'lidah' $\rightarrow$ mait jela 'manjur; bijak'

bajenta 'ramah' bajurah 'tamah' $\rightarrow$ bajenta bajurah 'ramah tamah' 


\subsection{Adjektiva dan Pertarafan}

Adjektiva dalam fungsinya

sebagai atribut nomina dapat menunjuk

tingkat kualitas dan tingkat bandingan.

Adjektiva dapat menunjuk tiga tingkat, yaitu

\section{Data 10}

(a) tingkat positif, yakni menerangkan bahwa nomina dalam keadaan biasa. Contoh:

(4) Human Jagau hai. 'Rumah si Jagau besar.'

(4a) Human Jagau sama kahai dengan humangku.

'Rumah Jagau sama besarnya dengan rumahku.'

(b) tingkat komparatif, yakni menerangkan bahwa suatu nomina melebihi keadaan nomina lain, misalnya:

(5) Human Jagau labih hai bara humangku.

'Rumah si Jagau lebih besar dari rumahku.'

(c) tingkat superlatif, yakni menerangkan bahwa keadaan nomina melebihi keadaan beberapa atau semua nomina lain yang dibandingkannya, misalnya:

(6) Nyai murid je pangka harati hung sakula.

'Nyai murid yang paling pintar di sekolah.' (6a) Nyai murid je harati tutu hung sakula.

'Nyai murid yang pintar sekali di sekolah.'

\section{Penutup}

Dalam penelitian ini, ditemukan bahwa adjektiva BDNg dapat ditandai dengan ciri, yaitu (1) ada kemungkinan untuk bergabung dengan partikel beken 'bukan' dan dia 'tidak'(2) dapat mendampingi nomina, atau (3) dapat didampingi kata labih 'lebih', pangka 'paling', tutu 'sangat', dan labien 'sangat'. Sedangkan berdasarkan variasi bentuk, adjektiva BDNg dapat dibedakan jenisnya atas adjektiva dasar dan adjektiva turunan. Adjektiva dasar adalah adjektiva yang hanya terdiri atas satu morfem. Sementara itu, adjektiva turunan $\mathrm{BDNg}$ mempunyai bentuk turunan yang terbentuk melalui proses pindah kelas kata dan proses morfologis, yaitu afiksasi, reduplikasi, dan pemajemukan.

Berdasarkan katergorinya, adjektiva BDNg hanya ada satu kategori adjektiva, yaitu adjektiva predikatif. 
Adjektiva predikatif adalah adjektiva yang dapat menempati posisi predikat dalam klausa. Selanjutnya, dalam pembentukannya, adjektiva $\mathrm{BDNg}$ dibentuk melalui beberapa proses afiksasi, reduplikasi, dan pemajemukan.

\section{Daftar Pustaka}

Alwi, Hasan et al. (2000). Tata Bahasa Baku Bahasa Indonesia, Edisi Ketiga. Jakarta: Balai Pustaka.

Bingan, Albert dan Offeny Ibrahim. (2001). Upon Ajar Basa Dayak Ngaju (Pokok Pelajaran Bahasa Dayak Ngaju). Palangka Raya: Primal Indah.

Bingan, Albert dan Offeny Ibrahim. (2005). Kamus Dwibahasa Dayak Ngaju-Indonesia. Palangka Raya: Primal Indah.

Chaer, Abdul. (2008). Morfologi Bahasa Indonesia. Jakarta: Rineka Cipta.

Ibrahim, Offeny A. dan Albert A. Bingan. (2005). Kamus Dwibahasa Dayak Ngaju-Indonesia. Palangka Raya: Primal Indah.

Kridalaksana, Harimurti. (1988). Beberapa Prinsip Perpaduan Leksem dalam Bahasa Indonesia. Yogyakarta: Kanisius.

Kridalaksana, Harimurti. (2001). Kamus Linguistik. Edisi Ketiga. Jakarta: Gramedia Pustaka Utama.
Kridalaksana, Harimurti. (2007). Kelas Kata dalam Bahasa Indonesia. Edisi Kedua. Jakarta: Gramedia Pustaka Utama.

Mahsun. (2005). Metode Penelitian Bahasa: Tahapan Strategi, Metode, dan Tekniknya. Jakarta: PT Raja Grafindo Persada.

Ramlan, M. (1981). Ilmu Bahasa Indonesia: Sintaksis. Yogyakrta: C.V Karyono.

Santoso, Mulyani Dewi dkk. (1991). Struktur Bahasa Dayak Ngaju. Laporan Penelitian. Palangka Raya: Universitas Palangka Raya. 